\title{
The effects of minor and moderately severe accidental chest injuries on pulmonary function in man
}

R. A. LitTle,* D. W. YATES, ROSALIND E. ATKINS, PAMELA BITHELL AND M. STANSFIELD

MRC Trauma Unit, *Manchester and Hope Hospital, Salford

SUMMARY

Pulmonary function has been measured at intervals after direct chest injuries of mild and moderate severity in 46 patients. Ventilatory capacity (e.g. $\mathrm{FEV}_{1}$ ) and vital capacity were reduced and the residual volume was increased. Total lung capacity and alveolar volume were also reduced and as a result total pulmonary diffusing capacity (transfer factor) was decreased, however, the remaining lung had a normal diffusion coefficient. Intercostal nerve block at the fracture site did not improve ventilatory capacity although marked pain relief was achieved. Recovery was slower in those patients not admitted to hospital than in the more seriously injured patients who were admitted. It is suggested that more attention should be paid to the outpatient follow-up of such patients, perhaps paying particular attention to physiotherapy.

\section{INTRODUCTION}

There is continuing interest in the role of the lung in the general response to injury and in the pathogenesis of the pulmonary complications of injury, commonly referred to as shock lung, ARDS etc., (e.g. Sykes, 1976). Studies have also been made of the functional sequelae of major direct chest injuries requiring admission to an intensive care unit (Davidson et al., 1969; Hanning et al., 1981). Somewhat surprisingly much less attention has been given to the changes in pulmonary function produced by the mild or moderately severe accidental injuries to the chest which occur so much more frequently. After such injuries the patients are not always admitted to hospital and are often sent home from the

Correspondence: $\operatorname{Dr} R$. A. Little, MRC Trauma Unit, Stopford Building, University of Manchester Medical School, Oxford Road, Manchester M13 9PT 
accident and emergency department without any assessment being made of their pulmonary function.

We have studied pulmonary function in a group of patients at intervals after accidentak chest injuries involving the fracture of at least one rib. The simple tests used were? selected to measure ventilatory capacity, lung volumes and diffusion capacity. A group of control subjects were also studied to determine the reproducibility of the tests and the effects of posture on pulmonary function. Some of the data has been presented in preliminary communication (Bancewicz et al., 1982).

\section{PATIENTS AND METHODS}

A total of 46 patients (six females) were studied, all of whom had sustained an accidenta® fracture of at least one rib. Whenever possible the first series of measurements were madein the accident and emergency department after X-ray confirmation of the injury Subsequent measurements were made on the wards or following recall to the accidente and emergency department. The injuries were graded according to the Abbreviated Injury Scale (AIS) (Baker $e t$ al., 1974) and an Injury Severity Score (ISS) was calculated $\vec{z}$ This method which has been validated (Stoner et al., 1977; Stoner et al., 1980), enables different types of injury to be placed on the same scale. Examples of representative chest ${ }^{-}$ injuries and their AIS values are shown in Table 1.

Table 1 Abbreviated Injury Scale (AIS) values for representative thoracic injuries

\begin{tabular}{ll}
\hline INJURY & AIS \\
\hline Fracture one rib & 1 \\
Fracture three adjacent ribs & 2 \\
Pneumothorax & 3 \\
Flail chest & 4 \\
\hline
\end{tabular}

The tests of pulmonary function used can be divided into measurements of ventilatory capacity, diffusing capacity and lung volumes. Ventilatory capacity was assessed by the forced expired volume measured over one second $\left(\mathrm{FEV}_{1.0}\right)$ and the forced vital capacity? using a wedge spirometer (Vitalograph, Buckingham, England). The best of three attempts was taken and the volumes expressed at BTPS. In some subjects the peak flow rate (PFR) was obtained from the maximal expiratory flow-volume curve recorded on a X-Y plotter (Gould Bryans Instruments, Mitcham, Surrey) connected to the spirometero of a Morgan lung function analyser (TLC System, P. K. Morgan, Chatham, Kent) Diffusing capacity was assessed by the measurement of the transfer factor $\left(T_{L}\right)$ for carbon ${ }^{\circ}$ monoxide using a single breath method (TLC System, P. K. Morgan, Chatham, Kent) as described by Cotes (1979). The TLC System was mounted on a converted hospitak trolley so that if necessary the equipment could be taken to the patient's bed-side in the accident and emergency department or general ward. The diffusing capacity wase expressed as both the transfer factor $\left(\mathrm{ml}, \mathrm{min}^{-1}, \mathrm{~mm} \mathrm{Hg}^{-1}\right)$ and as the transfer coefficien or diffusing constant $\left(\mathrm{K}_{\mathrm{CO}}\right)$ which takes the alveolar volume into account $\left(\mathrm{ml} \mathrm{CO}, \mathrm{min}^{-1}, \frac{0}{0}\right.$ 
mm Hg ${ }^{-1}, 1^{-1}$ ) (Cotes, 1979; Lipscomb et al., 1978; Werner \& Kolmer, 1982). When low values were obtained for $T_{L}$ it was sometimes possible to check whether this was due to a true deficit in diffusing capacity or to poor intrapulmonary mixing by recalculating alveolar volume from the functional residual capacity (and hence residual volume) measured with the closed-circuit helium dilution test (TLC System, P. K. Morgan, Chatham, Kent). Unfortunately this could not be done in all cases because some patients were unable to tolerate the mouth piece and nose clip for the several minutes needed for full equilibration. Patients who had recently smoked a cigarette or who admitted to being heavy smokers were excluded from this test. The total lung capacity (TLC) was calculated as the inspiratory capacity plus the functional residual capacity. Inspiratory capacity was measured from the spirometer tracing and the functional residual capacity by the helium dilution test mentioned above. The vital capacity (VC) was calculated as the sum of the inspiratory capacity and the expiratory reserve volume measured on the spirometer tracing (Cotes, 1979). The residual volume was taken as the difference between TLC and VC.

Predicted values were taken from Cotes (1979) and the Vitalograph lung function tables and nomograms.

A record was kept of the patient's clinical course, paying particular attention to analgesic drugs given (Entonox was not used) and posture during the tests. Intercostal nerve block was achieved with the injection of $2 \mathrm{ml}$ of $0.25 \%$ bupivacaine (Marcain Plain, Duncan Flockhart) at each fracture site.

Thirteen control subjects were studied under similar conditions (i.e. lying supine or sitting on an examination trolley in the accident and emergency department).

The results were analysed statistically by standard methods (Snedecor \& Cochran, 1967). The studies were approved by the Salford Health Authority Ethical Committee.

\section{RESULTS}

Some details of the controls and the patients are shown in Table 2. Four of the AIS 1, three of the AIS 2 and all of the AIS 3 patients were admitted to hospital. None of the patients had a fracture of the first or second ribs and none died from their injuries. Only four $(16 \%)$ of the AIS 1 patients had other injuries (ISS range 2-11) but this increased to seven $(58 \%$ ) in the AIS 3 group (ISS range 10-17), none of these 'multiply' injured patients had an abdominal injury. Nearly one half $(22)$ of the patients were injured in road traffic or occupational accidents, the remainder were the victims of a variety of accidents including assaults, domestic falls, sporting injuries, falls on ice etc. The first tests were made $0.75 \mathrm{~h}-15$ days (median $13.5 \mathrm{~h}$ ) after injury. The long time intervals between injury and first measurement in some patients were a result of delays in presentation to hospital in the AIS 1-2 groups and to an inability to co-operate with the tests in the AIS 3 group. Eleven of the patients who were admitted (AIS 1, 2; AIS 3, 9) were given pethidine (50-100 mg i.m.) at intervals for up to five days after admission followed in some cases by oral analgesics (DF118, one; paramol, two; distalgesic, three; fortral, one or omnopon, one). Another 11 patients who were not admitted were prescribed oral analgesics (equagesic, 5; distalgesic, 2; zomax, 3; paramol, 1). 
Table 2 Clinical features of patients and control subjects

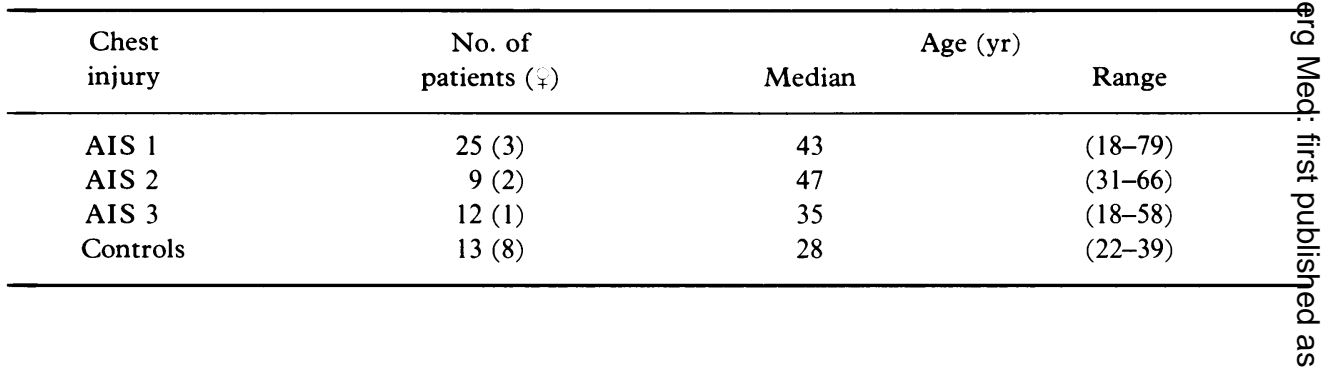

Pulmonary function was measured in five control subjects four or five times over a tw $\vec{\emptyset}$ month period. The coefficient of variation for the measurements were: forced expired volume $_{1.0}(1.8 \%)$, transfer factor $(8 \cdot 7 \%)$, transfer coefficient $(6.6 \%)$ and total lung capacity $(5.0 \%)$. The effect of posture on pulmonary function was assessed in 11 controf subjects. Forced expired volume . $_{10}$ was significantly higher $(\mathrm{p}<0.05$; paired ' $\mathrm{t}$ ' test) i⿳亠丷冖. the upright $(3.49 \pm 0.301)$ than in the supine $(3.21 \pm 0.221)$ position. Total lung capacit $\vec{\psi}$ was not affected by posture but both transfer factor and transfer coefficient wer? significantly lower $\left(\mathrm{p}<0.05\right.$; paired ' $\mathrm{t}$ ' test) in the upright $\left(\mathrm{T}_{\mathrm{L}} 29.3 \pm 1.5 \mathrm{ml} \mathrm{CO} \mathrm{min}-\mathrm{D}\right.$

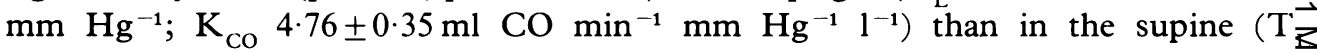
$33 \cdot 2 \pm 2 \cdot 1 \mathrm{ml} \mathrm{CO} \mathrm{min}^{-1} \mathrm{~mm} \mathrm{Hg}^{-1} ; \mathrm{K}_{\mathrm{CO}} 5 \cdot 52 \pm 0 \cdot 33 \mathrm{ml} \mathrm{CO} \mathrm{min}^{-1} \mathrm{~mm} \mathrm{Hg}^{-1} \mathrm{l}^{-1}$ ) position

\section{Ventilatory Capacity after Injury}

$\mathrm{FEV}_{1 \cdot 0}$ was significantly lower than the predicted normal value after chest injuries of both minor (AIS 1-2) and moderate (AIS 3) severity (Table 3). On the day of injury an for the next two days the reduction was greater in the moderately injured patients Subsequently $\mathrm{FEV}_{1.0}$ slowly returned to predicted values in the AIS 3 patients bu政 remained markedly impaired in the AIS 1-2 group. A similar pattern of reduction i ventilatory capacity after injury was shown by the peak flow rates (Fig. 1). The shape of

Table 3 Effect of direct chest injury on forced expired volume ${ }_{1.0}\left(\mathrm{FEV}_{1}\right)$

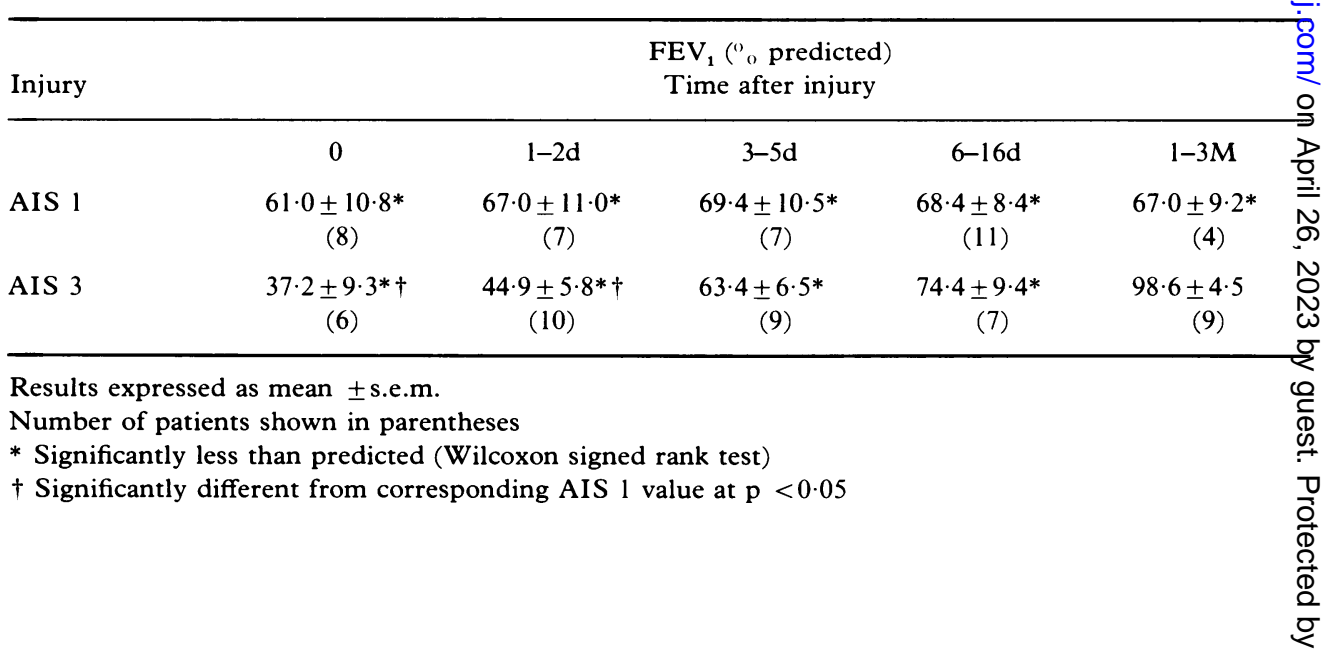




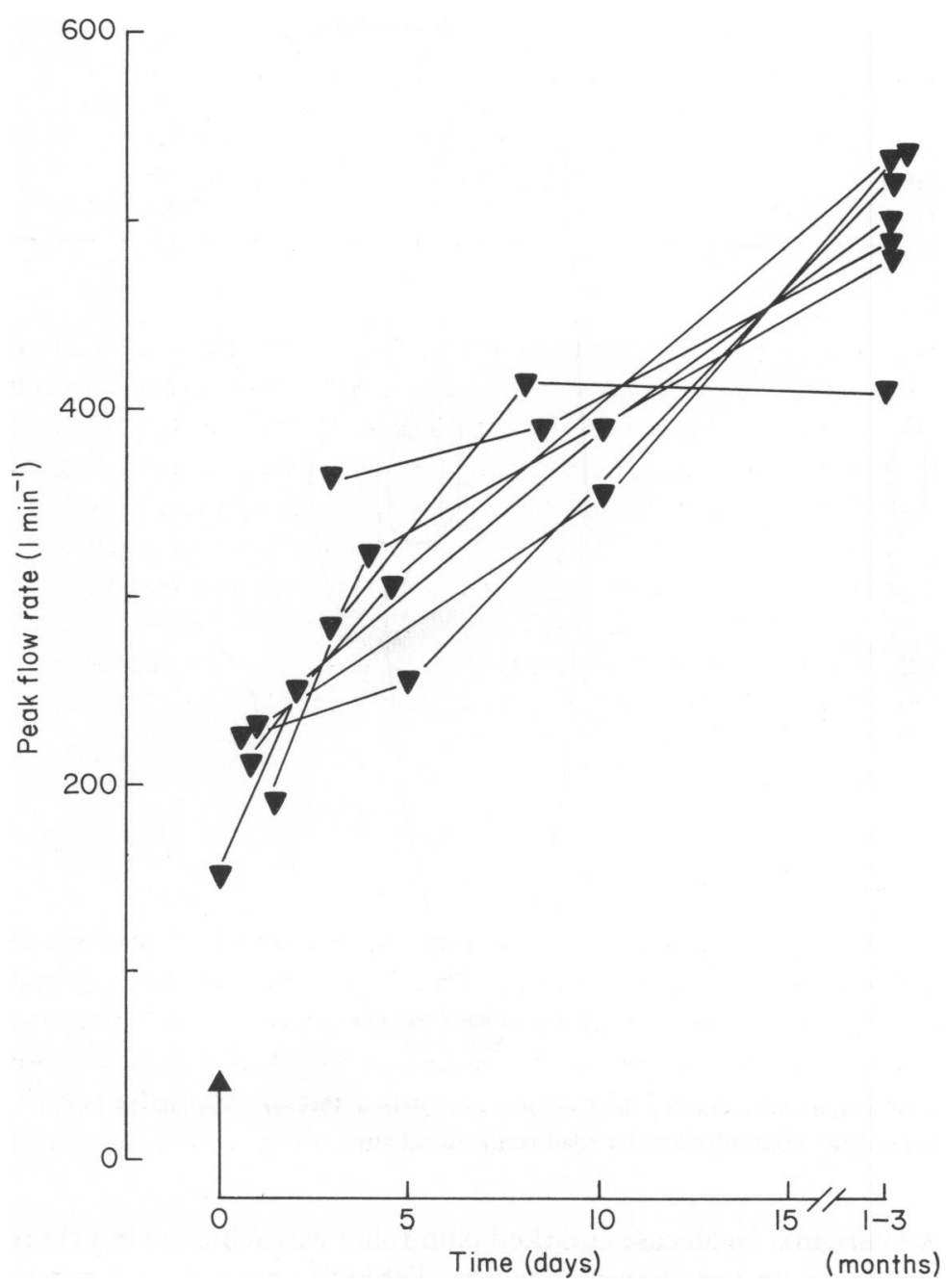

Fig. 1 Peak flow rates $\left(\mathrm{L} \mathrm{min}^{-1}\right)$ calculated from flow-volume curves (e.g. Fig. 1B) in seven patients after direct chest injuries of moderate severity (AIS 3). Time of accident on Day 0 is indicated by the arrow.

the flow-volume curves (e.g. Fig. 2) suggested that the impairment in ventilatory capacity was restrictive rather than obstructive in origin and this was confirmed when $\mathrm{FEV}_{1.0}$ was expressed as a percentage of the forced vital capacity (FVC). In a group of 18 patients 10 had a higher $\mathrm{FEV}_{\%}$ on the day of injury than after recovery. In four $\mathrm{FEV} \%$ was unchanged and in only four was $\mathrm{FEV} \%$ reduced immediately after injury, this may not reflect an obstructive lesion but may well be a result of the patient's reluctance to make a maximal expiratory effort. The effect of intercostal nerve block at the site of rib 


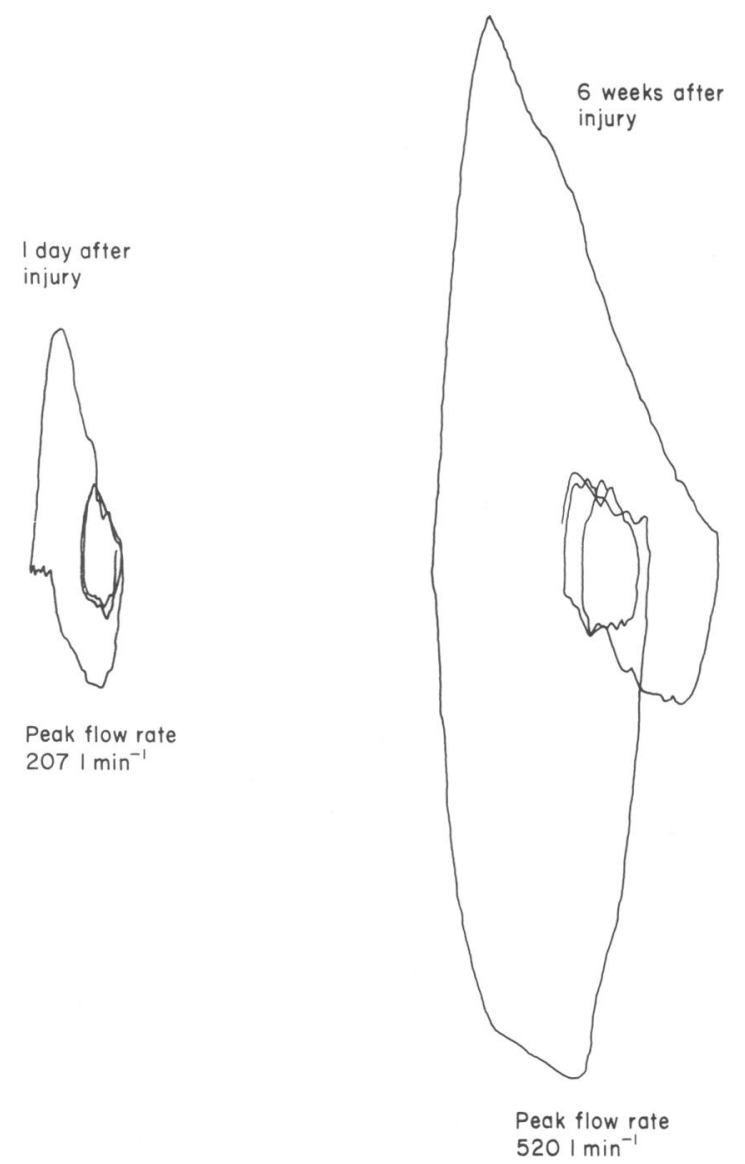

Fig. 2 Illustrative examples of maximal expiratory flow-volume curves in a 30-year-old male 14 hours and six weeks after the fracture of six adjacent ribs in a road traffic accident.

fracture was tested in five patients. In all cases marked pain relief was achieved but therğ was no significant improvement in ventilatory capacity (Table 4 ).

\section{Diffusing Capacity after Injury}

Only a relatively small number of the injured patients was able to co-operat鸟 satisfactorily in this test and so the results from the AIS 1,2 and 3 groups have had to be combined. There was a significant reduction in transfer factor (expressed as $\mathrm{ml} \mathrm{Cळ్టు}$ $\min ^{-1} \mathrm{~mm} \mathrm{Hg}^{-1}$ or as a \% predicted) for approximately the first week after injury (Table 5). In those patients in whom it was also possible to carry out the longer helium dilutiom

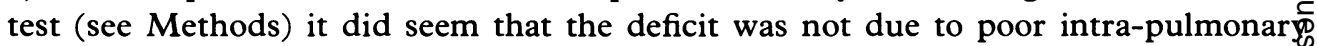
mixing. However when the diffusing capacity was expressed as the transfer coefficient (i.e. by taking the alveolar volume into account) there was no significant reduction afte $\overline{\mathrm{B}}$ 
Table 4 Effect of intercostal nerve block (Marcain $0 \cdot 25^{\circ}$ ) at the site of rib fracture on ventilatory capacity.

\begin{tabular}{|c|c|c|c|c|c|}
\hline Patient & $\begin{array}{l}\text { Injury } \\
\text { (AIS) }\end{array}$ & $\begin{array}{l}\text { Block } \\
(-/+)\end{array}$ & $\begin{array}{l}\text { Forced vital } \\
\text { capacity (L) }\end{array}$ & $\begin{array}{l}\text { Forced expired } \\
\text { volume }(\mathrm{L})\end{array}$ & $\mathrm{FEV}^{\circ}{ }_{0}$ \\
\hline 1289 & 3 & $\begin{array}{l}- \\
+ \\
\mathrm{R}^{*}\end{array}$ & $\begin{array}{l}1 \cdot 23 \\
1 \cdot 15 \\
4.50\end{array}$ & $\begin{array}{l}1.08 \\
0.98 \\
3.08\end{array}$ & $\begin{array}{l}87 \cdot 9 \\
85 \cdot 2 \\
68 \cdot 4\end{array}$ \\
\hline 1421 & 2 & $\begin{array}{l}- \\
+ \\
\mathbf{R}\end{array}$ & $\begin{array}{l}2 \cdot 44 \\
2 \cdot 42 \\
3 \cdot 40\end{array}$ & $\begin{array}{l}1.89 \\
1.79 \\
2.50\end{array}$ & $\begin{array}{l}77 \cdot 3 \\
73 \cdot 9 \\
73 \cdot 5\end{array}$ \\
\hline 1547 & 3 & $\begin{array}{l}- \\
+ \\
\mathbf{R}\end{array}$ & $\begin{array}{l}1.49 \\
1.84 \\
3.22\end{array}$ & $\begin{array}{l}0.86 \\
1 \cdot 11 \\
2 \cdot 33\end{array}$ & $\begin{array}{l}57 \cdot 5 \\
60 \cdot 3 \\
72 \cdot 4\end{array}$ \\
\hline 1555 & 2 & $\begin{array}{l}- \\
+ \\
\mathbf{R}\end{array}$ & $\begin{array}{l}1 \cdot 10 \\
1 \cdot 18 \\
1 \cdot 33\end{array}$ & $\begin{array}{l}0.70 \\
0.65 \\
0 \cdot 66\end{array}$ & $\begin{array}{l}63 \cdot 3 \\
55 \cdot 0 \\
49 \cdot 6\end{array}$ \\
\hline 1600 & 2 & $\begin{array}{l}- \\
+ \\
\mathbf{R}\end{array}$ & $\begin{array}{c}2 \cdot 30 \\
2 \cdot 42 \\
\text { । }\end{array}$ & $\begin{array}{c}2.00 \\
2.08 \\
\end{array}$ & $\begin{array}{c}87 \cdot 0 \\
85 \cdot 9 \\
/\end{array}$ \\
\hline
\end{tabular}

Tests performed immediately before and 5-60 min (median $45 \mathrm{~min}$ ) after nerve block.

* Values obtained on 'recovery' at least one month after injury.

injury (Table 5) and the values obtained were very similar to those obtained in the control uninjured subjects.

\section{Lung Volumes after Injury}

The data from the AIS 1, 2 and 3 groups have again been combined. Total lung capacity (TLC) was significantly lower than the predicted value on days 1-5 after injury although it was not significantly reduced on the day of injury (Table 6). Vital capacity (VC) was significantly reduced for at least 16 days after injury. The reduction in VC seemed to be proportionately greater than that in TLC and not surprisingly residual volume (expressed as a percentage of TLC) was significantly greater during the first week after injury than at recovery 1-3 months later (Table 6).

\section{DISCUSSION}

This study shows that direct chest injuries of mild and moderate severity lead to a significant impairment of pulmonary function. The changes are too large to be explained by altered posture or by the normal fluctuations over a 2-3 month time interval of the measurements used to assess pulmonary function.

The reduction in ventilatory capacity after injury was the most marked change. It did 
Table 5 Effect of direct chest injury on transfer factor $\left(\mathrm{T}_{\mathrm{L}}\right)$ and transfer coefficient $\left(\mathrm{K}_{\mathrm{Co}}\right)$. Results for injur severities AIS 1, 2 and 3 combined.

\begin{tabular}{|c|c|c|c|c|}
\hline \multirow{2}{*}{$\begin{array}{l}\text { Time } \\
\text { after } \\
\text { Injury }\end{array}$} & \multirow{2}{*}{$\begin{array}{l}\text { Number } \\
\text { of } \\
\text { Patients }\end{array}$} & \multicolumn{2}{|c|}{$T_{L}$} & \multirow{2}{*}{ 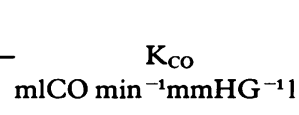 } \\
\hline & & $\left(\mathrm{mlCO} \mathrm{min}^{-1} \mathrm{mmHg}\right)$ & ( $\%$ Predicted $)$ & \\
\hline 0 & 7 & $23 \cdot 2 \pm 2 \cdot 6 * *$ & $75 \cdot 4 \pm 11 \cdot 2 *$ & $4 \cdot 23 \pm 0 \cdot 59$ \\
\hline $1-2$ days & 9 & $29 \cdot 7 \pm 2 \cdot 8$ & $84 \cdot 8 \pm 7 \cdot 0 *$ & $4.93 \pm 0.23$ \\
\hline 3-5 days & 12 & $23 \cdot 4 \pm 1 \cdot 3 \dagger$ & $79 \cdot 3 \pm 4 \cdot 2 *$ & $4 \cdot 38 \pm 0 \cdot 28$ \\
\hline 6-16 days & 14 & $25 \cdot 3 \pm 1 \cdot 9$ & $82 \cdot 3 \pm 4 \cdot 7 *$ & $4 \cdot 37 \pm 0 \cdot 16$ \\
\hline 1-3 months & 15 & $30 \cdot 2 \pm 1 \cdot 8$ & $99 \cdot 1 \pm 4 \cdot 7$ & $4 \cdot 56 \pm 0 \cdot 19$ \\
\hline
\end{tabular}

Results expressed as mean \pm s.e.m.

Day 0 represents day of accident

* Significantly less than predicted $\mathrm{p}<0.05-0.01$ (Wilcoxon signed rank test)

** Significantly lower than corresponding 1-3 month value at $\mathrm{p}<0.05$

$\dagger$ Significantly lower than corresponding $1-3$ month value at $\mathrm{p}<0.01$

Table 6 Effects of direct chest injury on total lung capacity (TLC), vital capacity (VC) and residual volume $\overrightarrow{\vec{e}}$ expressed as a percentage of total lung capacity $(\mathrm{RV} \%)$. Results from injury severities AIS 1,2 and 3 combined.

\begin{tabular}{|c|c|c|c|c|}
\hline $\begin{array}{l}\text { Time after } \\
\text { injury }\end{array}$ & $\begin{array}{c}\text { TLC } \\
\text { (\% Predicted) }\end{array}$ & $\begin{array}{c}\text { VC } \\
(\% \text { Predicted })\end{array}$ & $\mathbf{R V} \%$ & مْ \\
\hline 0 & $\begin{array}{c}87 \cdot 3 \pm 9 \cdot 1 \\
\quad(10)\end{array}$ & $\begin{array}{l}72 \cdot 3 \pm 7 \cdot 0 \dagger \\
\quad(12)\end{array}$ & $\begin{array}{c}40 \cdot 6 \pm 4 \cdot 7^{*} \\
\quad(10)\end{array}$ & 引 \\
\hline 1-2 days & $\begin{array}{l}75 \cdot 5 \pm 4 \cdot 9 \dagger \\
\quad(12)\end{array}$ & $\begin{array}{l}57 \cdot 4 \pm 4 \cdot 9 \dagger \\
\quad(12)\end{array}$ & $\begin{array}{c}45 \cdot 9 \pm 2 \cdot 9 * * \\
\quad(12)\end{array}$ & D \\
\hline 3-5 days & $\begin{array}{l}82 \cdot 3 \pm 6 \cdot 9 \dagger \\
\quad(12)\end{array}$ & $\begin{array}{l}67 \cdot 9 \pm 5 \cdot 5 \dagger \\
(14)\end{array}$ & $\begin{array}{l}39 \cdot 8 \pm 3 \cdot 8 * \\
\quad(12)\end{array}$ & \\
\hline $6-16$ days & $\begin{array}{c}96 \cdot 9 \pm 6 \cdot 8 \\
\quad(15)\end{array}$ & $\begin{array}{l}75 \cdot 9 \pm 5 \cdot 4 \dagger \\
(16)\end{array}$ & $\begin{array}{c}35 \cdot 9 \pm 2 \cdot 6 \\
\quad(15)\end{array}$ & \\
\hline $1-3$ months & $\begin{array}{c}111 \cdot 1 \pm 3 \cdot 3 \\
(14)\end{array}$ & $\begin{array}{c}92 \cdot 3 \pm 6 \cdot 0 \\
\quad(14)\end{array}$ & $\begin{array}{l}29 \cdot 5 \pm 2 \cdot 3 \\
\quad(14)\end{array}$ & D. \\
\hline \multicolumn{5}{|c|}{$\begin{array}{l}\text { Results expressed as mean } \pm \text { s.e.m. } \\
\text { Day } 0 \text { represents day of injury } \\
\dagger \text { Significantly less than predicted } p<0.05-0.001 \text { (Wilcoxon signed rank test) } \\
\text { * Significantly different from corresponding } 1-3 \text { month value at } p<0.05 \\
\text { ** Significantly different from corresponding } 1-3 \text { month value at } p<0.001\end{array}$} \\
\hline
\end{tabular}


not appear to be due to obstruction of the lung airways but rather to restricted expansion of the thorax a conclusion supported by the finding of a concomitant reduction in vital capacity and increase in residual volume. The inability to fully expand the thorax is presumably a result of both the physical damage to the chest wall and the pain produced (or anticipated) when the patient tries to take a deep breath. When ventilatory capacity was measured soon after injury the impairment was directly related to the severity of injury. The patients with more severe injuries (AIS 3) were admitted to hospital and with supervised physiotherapy soon started to improve. Indeed on follow-up 1-3 months after injury the ventilatory capacity had returned to predicted values confirming that such injuries do not usually leave any residual impairment of lung function (Braun et al., 1977). However, in those patients with minor injuries (such as the fracture of one rib) the deficit in vital capacity was more persistent. This may be explained by their reluctance to do any more than tidal breathing while unsupervised at home.

The use of analgesia would seem to be advisable but we have no evidence that pulmonary function was improved by the use of analgesics. There was no improvement in ventilatory capacity despite achieving marked pain relief with intercostal nerve blocks at the site(s) of fracture. This was unexpected and did not agree with the experience of others (e.g. Jones et al., 1967; Pedersen et al., 1983). It is of interest that there seems to be a dissociation between analgesia and the impairment of pulmonary function. Indeed preliminary results suggest that the injection of larger doses (4-5 $\mathrm{ml}$ at each site) of local anaesthetic than are needed to achieve analgesia may be more effective in helping to restore ventilatory capacity.

The diffusing capacity of the lung was also reduced after injury. This was a result of a reduction in alveolar volume rather than to a deficit in the alveolar capillary membrane. The unchanged transfer coefficient or diffusion constant after injury indicates that the parts of the lung still involved in gaseous exchange are normal and there is no evidence for diffuse pulmonary oedema. The reduction in alveolar volume (and total lung capacity) is probably due to collapse of that part of the lung which was directly damaged at the site of injury.

Thus after chest injuries of minor and moderate severity there is a reduction in total pulmonary diffusing capacity and an impairment of pulmonary ventilation which may compromise the ability to increase pulmonary gaseous exchange. This can be important if, for example, metabolic rate is increased secondary to a chest infection which develops because the patient is unable to cough sufficiently to clear pulmonary secretions. There is no doubt that in-patient treatment including physiotherapy was of considerable benefit in aiding recovery and it would seem sensible to pay more attention to the progress of the patient who is not admitted. We recommend that they should attend out-patient clinics where physiotherapy is encouraged and lung function can be assessed. The present study would seem to confirm the suggestion that 'simple' fractures are not such simple injuries (Cosgriff \& Hale, 1959). 


\section{REFERENCES}

Baker S. P., O’Neil B., Hadden W. \& Long W. B. (1974) The injury severity score: a method for describing patients with multiple injuries and evaluating emergency care. Fournal of Trauma 14, 187-96.

Bancewicz J., Bithell P., Little R. A., McBeath J., Stansfield M., Stoner H. B. \& Yates D. W. (1982) Pulmonary function after accidental injury and thoracotomy. In Progressive care of the acutely ill and injured. D. Wilsoß \& A. Marsden (eds), pp. 199-200.

Braun V., Munz E., Voigt E. \& Fassolt A. (1977) Pattern of respiratory function in the late post-traumati离 period after chest injury. Intensive Care Medicine 3 3, 186.

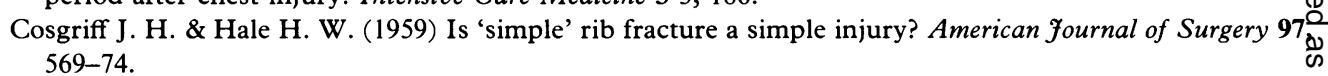

Cotes J. E. (1979) Lung Function. In Assessment and Application in Medicine. Oxford, Blackwell Scientifi $\overrightarrow{0}$ Publications.

Davidson I. A., Bargh W., Cruickshank A. N. \& Duthie W. H. (1969) Crush injuries of the chest. A follow-urf్రు study of patients treated in an artificial ventilation unit. Thorax 24, 563-7.

Hanning C. D., Ledingham E. \& Ledingham I. McA. (1981) Late respiratory sequelae of blunt chest injury: 2 . preliminary report. Thorax 36, 204-7.

Jones R. J., Samson P. C. \& Dugan D. J. (1967) Current management of civilian thoracic trauma. Americar Fournal of Surgery 114, 289-96.

Lipscomb D. J., Patel K. \& Hughes J. M. B. (1978) Interpretation of increases in the transfer coefficient fos carbon monoxide $\left(\mathrm{T}_{\mathrm{LCO}} / \mathrm{VA}\right.$ or $\left.\mathrm{K}_{\mathrm{CO}}\right)$. Thorax 33, 728-33.

Pedersen V. M., Schulze S., Høier-Madsen K. \& Halkier E. (1983) Air-flow meter assessment of the effect os intercostal nerve blockade on respiratory function in rib fractures. Acta Chirurgica Scandinavica $149 \frac{\bar{\sigma}}{\mathrm{D}}$ 119-20.

Snedecor G. W. \& Cochran W. G. (1967) Statistical Methods, 6E. Ames, Iowa. Iowa State University Press $\overrightarrow{0}$

Stoner H. B., Barton R. N., Little R. A. \& Yates D. W. (1977) Measuring the severity of injury. British Medi\&a Fournal ii, 1247-9.

Stoner H. B., Yates D. W., Frayn K. N. \& Heath D. F. (1980) Measuring the severity of injury. Fournal of 疋i Royal Society of Medicine 73, 19-22.

Sykes M. K. (1976) Pulmonary disturbances in shock. In Monographs in Anaesthesiology 4, Shock: Clinical anфu Experimental Aspects. I. McA. Ledingham (ed.). New York, Elsevier.

Werner F. \& Kolmer H. B. (1982) The CO single breath transfer factor of the lung, generally acceptable norma values. Pflügers Archiv. European Fournal of Physiology 393, 269-74.

Received 22 July 1983, accepted for publication 3 October 1983 